\title{
Spectral Characterization of Fungal Metabolites in Aqueous Medium with Humus Substances
}

\author{
D. A. Khundzhua, ${ }^{1}$ S. V. Patsaeva, ${ }^{1}$ V. A. Terekhova, ${ }^{2,3}$ and V. I. Yuzhakov ${ }^{1}$ \\ ${ }^{1}$ Faculty of Physics, Lomonosov Moscow State University, Moscow 119991, Russia \\ ${ }^{2}$ Faculty of Soil Science, Lomonosov Moscow State University, Moscow 119991, Russia \\ ${ }^{3}$ Institute of Ecology and Evolution, Russian Academy of Sciences, 33 Leninskiy Prospesct, Moscow 119071, Russia
}

Correspondence should be addressed to S. V. Patsaeva; spatsaeva@mail.ru

Received 30 June 2012; Accepted 6 September 2012

Academic Editor: Maciej Sitarz

Copyright (C) 2013 D. A. Khundzhua et al. This is an open access article distributed under the Creative Commons Attribution License, which permits unrestricted use, distribution, and reproduction in any medium, provided the original work is properly cited.

\begin{abstract}
The work is targeted to confirm participation of microscopic fungi in transformation of humus substances in aquatic environments. The research is focused on the spectroscopic study of the collection of fungal strains with different pigmentation of mycelium. Spectral properties of fungal metabolites were measured and compared to that of natural aquatic nonliving organic matter and commercial humus substances in aqueous solutions. The experiments revealed that the effect of microscopic fungi growing in the culture medium with added humate appeared as changes in the humic-type fluorescence: its characteristics became more similar to that of nonliving organic matter in natural waters than to original humate preparation. The experiments demonstrated degradation of coal-originated humate due to microbial activity into compounds of smaller molecular size and increased heterogeneity. We resume that transformation of humus substances by fungal cultures can be monitored and characterized using spectral measurements.
\end{abstract}

\section{Introduction}

Aqueous nonliving organic matter (NOM) and soil humus substances (HSs) are natural organic compounds representing the largest pool of carbon on the Earth [1]. Being the products of stochastic synthesis, NOM and HS were characterized as polydispersed substances having nonstoichiometric elemental composition with irregular and heterogeneous structures [2-5]. These natural substances are polymeric aromatic oxyacids of irregular structure with chemical properties which allow neutralizing hazardous effects of various pollutants [6, 7]. Commercial HS products are widely used in industry, agriculture, and in different technologies of wastewater treatment. For instance, very promising types of water-dispersible sorbents for heavy metal removal include hybrids consisting of magnetite nanoparticles coated by HS products [8-10].

The problem of interaction of HS and microscopic fungi in aqueous and terrestrial biocenoses provoked wide scientific discussions. It is well known that fungi are among the most diverse organisms in the world [11] and represent very important functional and structural component of biological ecosystems [12]. Fungal communities play a significant role in human well-being and ecological processes [13, 14]. Fungal natural habitats include soil, water, and various organisms. They are present in almost all regions and climates, even under extreme conditions. However their role in geochemical cycling usually remains underestimated. Nowadays, these microorganisms are widely used in biomedical research and biotechnology. In addition to direct benefit (sources of antibiotics) or adverse effects (agents of disease), microscopic fungi can impact many environmental processes, particularly those associated with the turnover of organic matter. The processes of soil organic matter transformation and regularities of utilization of plant residues by fungi were described in [1517]. Fungi affect the soil properties in different ways: via transformation of organic matter, via soil structure status, acidity, and temperature, as well as via the regulation of soil microbiota functioning. Fungi play an important role in plant litter decomposition through nutrient recycling because they 
attack the lignocellulose matrix that other organisms are unable to assimilate. Biodiversity and potential functions of microscopic fungi in aquatic ecosystems were shown in $[18,19]$.

Although it is debated whether microscopic fungi are capable to produce humus substances directly $[20,21]$, undoubtedly they play essential role in lignin degradation and humus substances turnover $[22,23]$. It was established that some fungi are capable to produce dark-brown polymers in the presence of dead plant biomass and thereby might contribute to the pool of humus or humic-like substances in salt marsh estuaries [24,25]. The fungal polymers resemble humus substances obtained from dead plant biomass or from salt marsh sediments in their elemental composition and elemental ratios, as well as the UV, visible, and FTIR spectral characteristics [26]. Comparative studies of fungal polymers-melanin and humin-like substances produced by individual and mixed cultures of basidiomycetes-showed their similarity in elemental composition and physicochemical properties to natural HS [27, 28]. Melanins are polymers of phenolic and/or indolic nature. The position of huminlike substances among other natural polymers formed under similar conditions, such as melanins and HS, is still not determined [28]. Studies of the dynamics of laccase production suggested that the humin-like substances were produced via extracellular degradation of lignin macromolecules with involvement of laccase, an extracellular oxidase of basidiomycetes [29].

The wood- and leaf-litter-decaying activity of basidiomycetes has been well known for a long time. Recently a great interest in studying the processes of organic matter turnover in soil and aqueous ecosystems is focused on nonbasidiomycetous microfungi, other important groups of soil and amphibious microscopic fungi like Deuteromycetes or ascomycetes. This interest is caused not only due to their ability to affect basidiomycetes activity using a set of exoenzymes [15], but as well as due to the direct participation of nonbasidiomycetous microscopic fungi in destruction of biopolymers and organic matter turnover [30]. Being destroyers of litter, dead branches, and tree trunks, including their constituent cellulose inaccessible to most organisms, microscopic fungi contribute significantly to the biological cycles of carbon. Interaction of microorganisms with NOM in aqueous and terrestrial biocenoses is an intriguing problem for our environment $[13,31]$. However the interaction of HS and microscopic fungi has not been studied much. The influence of commercial HS potassium humate on some physiological characteristics of microscopic fungi for the first time has been described in [32] for the cultures with differently pigmented mycelium. It was shown that addition of potassium humate in concentration of $0.1 \%$ or $0.02 \%$ by weight to the medium has accelerated the growth rate for the light-colored colonies and decelerated for the colonies with black and deep-brown pigmentation.

It is well established that fluorescence spectroscopy is an effective method for environmental monitoring and hydrographic measurements $[33,34]$, characterization of benthic organisms [35], algal cells [36, 37], corals [38] and higher plants [39-46], specification of photosynthetic pigments
[47-49], and other biological molecules [50, 51]. Spectral methods were successfully employed for studying NOM in natural water [52-59], as well as commercial HS preparations [60-63].

The results on fluorometric investigation of HS transformations caused by some microscopic fungi were reported in [64]. It was determined the ability of eight soil microfungal species, Alternaria alternata, Clonostachys rosea f. rosea, Exophiala cf. salmonis, Fusarium cf. coeruleum, Fusarium redolens, Paecilomyces lilacinus, Penicillium canescens, and Phoma sp., as well as two basidiomycetes Trametes versicolor and Phanerochaete chrysosporium to modify fluorescence properties of fulvic acids and humic acids.

Our work is aimed to confirm participation of microscopic fungi in transformation of humus substances. It is focused on fluorescence spectroscopic study of the collection of microfungal strains with different pigmentation of mycelium (from uncolored to dark colored), for which we previously revealed the dependence of growth rate on presence of humus substances in the medium [31]. The objective of the work is a detailed study of fluorescence properties (change of emission maximum, fluorescence quantum yield) of fungal metabolites in the medium without and in presence of commercial HS.

\section{Experimental}

We have analyzed six soil microfungal strains with different pigmentation of mycelium: Fusarium moniliforme (noncolored), Alternaria alternata (dark pigmented), Phoma glomerata (dark-brown pigmented), Cladosporium cladosporioides (dark pigmented), Geomyces pannorum (brown pigmented), and Mycelia sterilia (orange-brown pigmented). The fungi species were cultivated in the liquid Czapek medium with addition or without addition of potassium humate Powhumus, produced from brown coal leonardite, in concentration of $0.2 \mathrm{~g} / \mathrm{L}$. All cultures grew up in $200 \mathrm{~mL}$ glass flasks in darkness at temperature of 25 degrees. Several strains of micromycetes in parallel were studied in each experiment using at least three replicates for each strain. Time of cultivation varied from 2 to 6 weeks. Filtered culture fluid was used for further spectral investigations. Significant changes in fluorescence spectra due to the growth of microorganisms have been observed two-three weeks after beginning of fungi cultivation. Experiments with different cultures were repeated several times within two years period. Experiments with C. cladosporioides, Ph. glomerata, and M. sterilia were carried out 3 times; other cultures were investigated twice. Each repetition of the experiment with the same strain showed similar basic trends (the tendency to change the maximum of emission spectrum to shorter wavelengths, changes in the fluorescence quantum yield), although those quantitative values varied in up to $10 \%$.

Absorption spectra were measured using UV-Vis spectrophotometer Unico-2804 for filtered samples without dilution in relation to the Czapek medium without HS. For fluorescence measurements fungal metabolites were diluted in 10 times. Fluorescence emission spectra were registered with excitation at 270,310 , or $355 \mathrm{~nm}$ using luminescence 


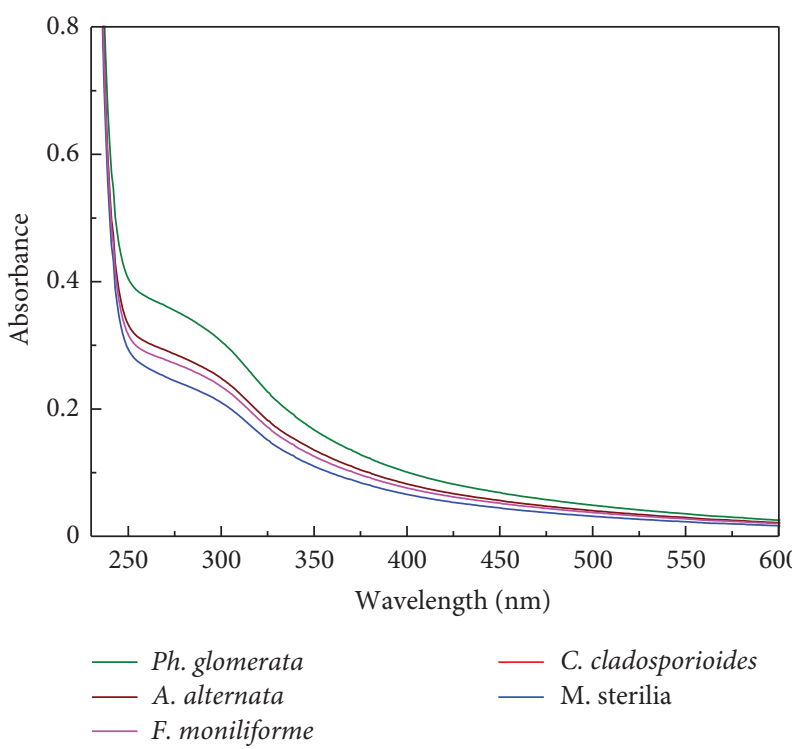

FIGURE 1: Absorption spectra of fungal metabolites for different cultures grown without humate in the medium.

spectrometer Solar CM2203. The choice of excitation wavelength was based on previous reports on studying spectral components of chromophoric NOM [56-58]. All spectra were registered in standard quartz cells with $1 \mathrm{~cm}$ optical path. The fluorescence quantum yield (FQY) for each excitation wavelength was calculated using a reference sample with known quantum yield. As a reference sample the solution of quinine sulphate was used, because of similarity of its fluorescence band to NOM or HS spectral band, both in shape and maximum position. The FQY of quinine sulphate dissolved in aqueous solution of sulphuric acid in water with concentration $0.05 \mathrm{~mole} / \mathrm{L}$ is equal to 0.546 [65]. Instrumental error of the absorbance values was 0,005 . In fluorescence measurement, the instrumental error was less than $5 \%$ for fluorescence intensity at a specific wavelength and less that $0,04 \%$ for its integral value. The error in finding fluorescence peak position was about $5 \mathrm{~nm}$. The relative error in calculation of FQY did not exceed $10 \%$ of its value.

\section{Results and Discussion}

3.1. Absorption Spectra. Figure 1 shows absorption spectra of filtered fungal cultural liquid measured in relation to the Czapek medium. Each spectral curve is an average of three culture replicates grown in the liquid medium without HS during three weeks.

Absorption spectra of fungal metabolites typically are featureless, with a monotonic decline with wavelength increasing from 200 to $600 \mathrm{~nm}$. In certain wavelength ranges, there is appearance of natural chromophoric groups. We attribute them as absorption band of phenolics and quinones ( $\mathrm{a}$ shoulder located around 280-290 nm).

3.2. Fluorescence Spectra. Fluorescence of fungal metabolites was observed in the spectral range of 280-600 nm (Figures 2

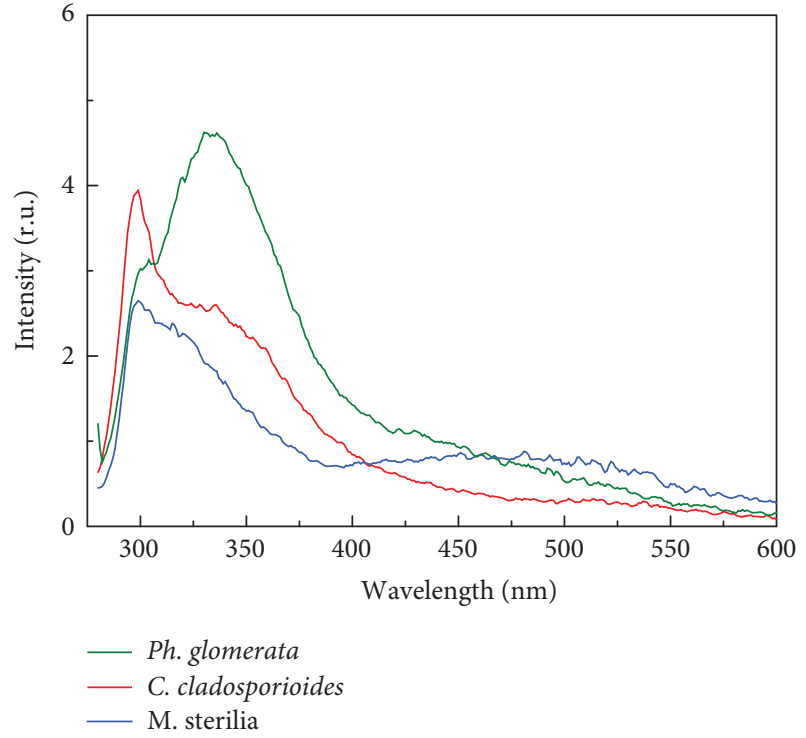

FIGURE 2: Fluorescence spectra of fungal metabolites for cultures grown without humate in the medium (excitation at $270 \mathrm{~nm}$ ).

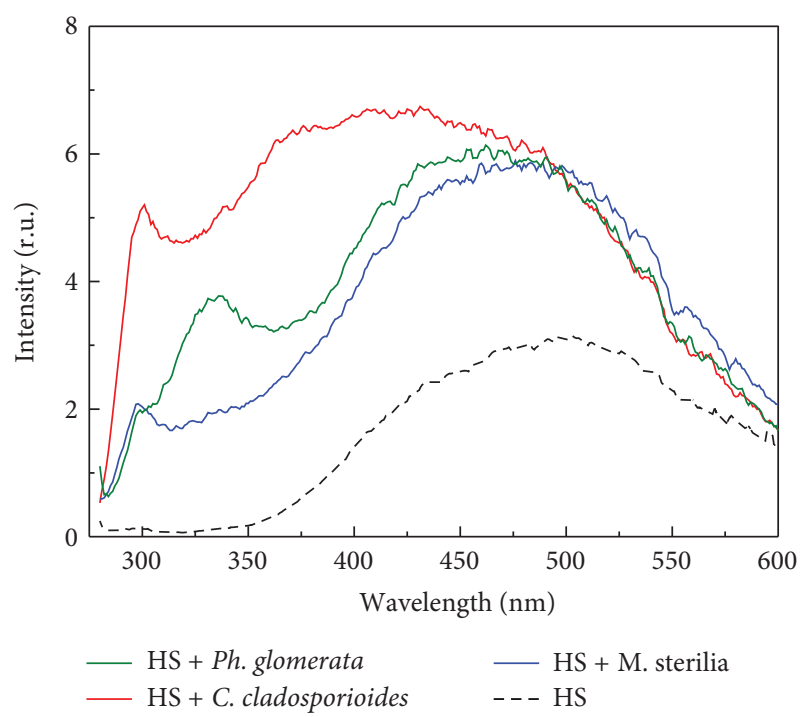

FIGURE 3: Fluorescence spectra of fungal metabolites for cultures grown in presence of humate in the medium (excitation at $270 \mathrm{~nm}$ ).

and 3). Typical fluorescence spectrum of fungal metabolites excited at $270 \mathrm{~nm}$ consists of two overlapping bands: (i) the UV fluorescence band within $300-350 \mathrm{~nm}$, attributed to phenolics and proteins and (ii) the blue fluorescence of fungal biopolymers within 400-600 $\mathrm{nm}$.

As it was preciously shown in experiments with natural water samples and aqueous soil extractions, typical fluorescence of natural HS (humic-type fluorescence) has emission maximum in the range of $420-460 \mathrm{~nm}$ [56-58], while fluorescence emission band of commercial HS products is shifted to the region of $500-520 \mathrm{~nm}[58,63]$, longer wavelengths compared to natural aquatic HS. 
TABLE 1: FQY and $\lambda_{\text {em }}$ for commercial HS solution and fungal metabolites of cultures grown in presence and absence of HS.

\begin{tabular}{|c|c|c|c|c|c|c|c|}
\hline \multirow{2}{*}{ FQY and $\lambda_{\mathrm{em}}$ (for given $\lambda_{\mathrm{ex}}$ ) } & \multirow{2}{*}{ HS solution } & \multicolumn{2}{|c|}{ C. cladosporioides } & \multicolumn{2}{|c|}{ Ph. glomerata } & \multicolumn{2}{|c|}{ M. sterilia } \\
\hline & & Without HS & With HS & Without HS & With HS & Without HS & With HS \\
\hline FQY $\left(\lambda_{e x}=270 \mathrm{~nm}\right)$ & $0.6 \%$ & $2.4 \%$ & $3.3 \%$ & $1.3 \%$ & $1.9 \%$ & $1.5 \%$ & $1.4 \%$ \\
\hline $\operatorname{FQY}\left(\lambda_{\mathrm{ex}}=310 \mathrm{~nm}\right)$ & $0.5 \%$ & $1.7 \%$ & $5.2 \%$ & $0.5 \%$ & $1.9 \%$ & $0.9 \%$ & $2.1 \%$ \\
\hline $\mathrm{FQY}\left(\lambda_{\mathrm{ex}}=355 \mathrm{~nm}\right)$ & $0.4 \%$ & $5.0 \%$ & $7.2 \%$ & $1.0 \%$ & $2.1 \%$ & $2.3 \%$ & $3.4 \%$ \\
\hline$\lambda_{\mathrm{em}}, \mathrm{nm}\left(\lambda_{\mathrm{ex}}=270 \mathrm{~nm}\right)$ & 498 & UV & 414 & UV & 423 & UV & 459 \\
\hline$\lambda_{\mathrm{em}}, \mathrm{nm}\left(\lambda_{\mathrm{ex}}=310 \mathrm{~nm}\right)$ & 501 & & 423 & & 435 & & 446 \\
\hline$\lambda_{\mathrm{em}}, \mathrm{nm}\left(\lambda_{\mathrm{ex}}=355 \mathrm{~nm}\right)$ & 500 & & 451 & & 465 & & 473 \\
\hline
\end{tabular}

Emission maximum position of natural aquatic HS depends on excitation wavelength $\lambda_{\text {ex }}$. The wavelength of maximum emission excited at $\lambda_{\mathrm{ex}}=310 \mathrm{~nm}$ shifts towards shorter wavelength compared to that excited at $270 \mathrm{~nm}$ or $355 \mathrm{~nm}$. This phenomenon was observed for all types of natural HS [56-58, 66, 67] and is known as "blue shift" of DOM fluorescence $[66,67]$. In contrast, the position of emission maximum for commercial HS does not depend on excitation wavelength $[58,63]$.

After fungi growing in the humate-containing medium, their fluorescence spectra consist of two broad overlapping bands: (i) the UV fluorescence of phenolics or proteins and (ii) the wide band around $425-470 \mathrm{~nm}$ conditional on fungal metabolite products (Figure 3). With $\lambda_{\mathrm{ex}}=310 \mathrm{~nm}$ the position of the second band is shifted towards shorter wavelengths compared to fluorescence of the same sample excited at $270 \mathrm{~nm}$ or $355 \mathrm{~nm}$. This resembles the spectral features of dissolved organic matter occurring in natural water [56-58]. This spectral behavior cannot be explained by simple addition of fluorescence bands for humate and fungal metabolites, since the blue fluorescence of fungal biopolymers is not strong enough to give such an effect.

3.3. Fluorescence Quantum Yield (FQY). The values of FQY for the humic-type fluorescence reside between $2-4 \%$ for NOM in natural water, $0.1-0.3 \%$ for aqueous soil extractions, and $0.4-1.2$ for commercial HS preparations in water [26, 27]. The value of FQY of most of natural HS increases along with the excitation wavelength rising from 270 to $355 \mathrm{~nm}$ [27]. Our experiments revealed that the effect of fungi growing with HS in the culture medium appeared as significant changes in the humic-type fluorescence (see Table 1 and Figure 3). The value of quantum yield of humictype fluorescence for HS modified by fungi increased and its emission maximum were essentially shifted towards shorter wavelengths compared to that for original humate solution.

Moreover, the spectral behavior of humic-type fluorescence along with excitation wavelength has been changed after growing of microfungal cultures. For original humate solution FQY was slightly decreasing with $\lambda_{\text {ex }}$ (Table 1). But due to fungi growing, the HS-containing culture medium demonstrated increase of FQY with $\lambda_{\mathrm{ex}}$. The peak wavelengths for the initial HS solution were about $500 \mathrm{~nm}$ and practically identical under different excitation wavelengths $\left(\lambda_{\mathrm{ex}}=270,310\right.$, or $\left.355 \mathrm{~nm}\right)$, while after culture growing its emission maximum became essentially dependent on excitation wavelength.

Significant transformation of humus substances due to the growth of microorganisms has been observed not earlier than two-three weeks after the start of cultivation. Table 1 summarizes the results for three fungal cultures which demonstrated the best reproducibility in our experiments after 3 weeks of cultivation. Other fungal cultures showed similar basic tendencies in spectral behavior after the same period of cultivation. Longer growing of fungal cultures caused the effects of mycelium autolysis.

The work [64] describes that some microfungal species shifted the emission maximum of fulvic and humic acids to longer wavelengths. The opposite effect (shift of the humic acids emission maximum to shorter wavelengths) caused by microscopic fungi was observed in [64] for humic acids complemented by glucose. In our research we did include sugar in the medium; however, we cannot directly compare our results with those of [64] because of the following two reasons. First, for fluorescence excitation we used the UV wavelengths ranging from 270 to $355 \mathrm{~nm}$, while in the authors of [64] excited fluorescence at 470 and $468 \mathrm{~nm}$. Second, in our study we have used commercial HS preparation from leonardite, while the paper [64] deals with fulvic and humic acids purified by column chromatography.

Our findings were explained by transformation of refractory HS from bigger to smaller macromolecules by fungi cultures during their growing. Microscopic fungi utilize big macromolecular compounds with longwave fluorescence emission and produce smaller ones with emission shifted towards shorter wavelengths. Dependence of the values of FQY and $\lambda_{\mathrm{em}}$ on $\lambda_{\mathrm{ex}}$ reflects heterogeneity of composition of substances in the culture medium. Thus, spectral characteristics of humate solution became more similar to that of NOM of natural water or soil HS.

For confirmation of the hypothesis we have made experiments to compare fluorescence of natural NOM of different molecular size and commercial humic acids. Test samples were taken from two rivers in Moscow region. These NOMcontaining samples were filtered through cellulose acetate filter with $5 \mathrm{~nm}$ pore size to get low-molecular weight fraction and analyzed with a fluorescence spectrometer. As a result of investigations we submit the list of spectral characteristics (see Table 2) of NOM in initial water sample and its low molecular weight fraction. Humic acid Aldrich was dissolved in water to receive the samples of commercial HS. 
TABLE 2: FQY and $\lambda_{\text {em }}$ for natural NOM and its low molecular weight fraction in comparison to solutions of commercial humic acids in water.

\begin{tabular}{|c|c|c|c|c|c|c|c|c|}
\hline FQY and $\lambda_{\mathrm{em}}$ (for given $\lambda_{\mathrm{ex}}$ ) & \multicolumn{3}{|c|}{$\mathrm{NOM}$ of natural water } & \multicolumn{3}{|c|}{ Low molecular weight fraction of NOM } & \multicolumn{2}{|c|}{ Commercial humic acids } \\
\hline $\mathrm{FQY}\left(\lambda_{\mathrm{ex}}=270 \mathrm{~nm}\right)$ & $1.8 \%$ & $2.7 \%$ & $2.6 \%$ & $2.2 \%$ & $4.0 \%$ & $3.9 \%$ & $1.3 \%$ & $1.3 \%$ \\
\hline $\mathrm{FQY}\left(\lambda_{\mathrm{ex}}=310 \mathrm{~nm}\right)$ & $2.5 \%$ & $3.2 \%$ & $3.4 \%$ & $3.0 \%$ & $4.8 \%$ & $3.9 \%$ & $1.2 \%$ & $1.2 \%$ \\
\hline $\mathrm{FQY}\left(\lambda_{\mathrm{ex}}=355 \mathrm{~nm}\right)$ & $3.6 \%$ & $3.9 \%$ & $5.0 \%$ & $5.0 \%$ & $7.2 \%$ & $5.7 \%$ & $1.0 \%$ & $1.1 \%$ \\
\hline$\lambda_{\mathrm{em}}, \mathrm{nm}\left(\lambda_{\mathrm{ex}}=270 \mathrm{~nm}\right)$ & 446 & 446 & 438 & 450 & 436 & 439 & 478 & 477 \\
\hline$\lambda_{\mathrm{em}}, \mathrm{nm}\left(\lambda_{\mathrm{ex}}=310 \mathrm{~nm}\right)$ & 428 & 421 & 420 & 424 & 420 & 423 & 475 & 475 \\
\hline$\lambda_{\mathrm{em}}, \mathrm{nm}\left(\lambda_{\mathrm{ex}}=355 \mathrm{~nm}\right)$ & 448 & 445 & 445 & 451 & 447 & 445 & 476 & 477 \\
\hline
\end{tabular}

Once again we have observed that emission maximum of commercial HS solutions is shifted to longer wavelength region compared to that of natural HS in water. The shift of emission to shorter wavelengths, or so-called "blue shift" was observed for natural water with change in excitation wavelength from 270 to $310 \mathrm{~nm}$, and it did not occur for humic acid solutions. We can resume that for low-molecular weight fraction of NOM the value of FQY is higher than the same value for the initial NOM, which proves the hypothesis that microscopic fungi break macromolecular HS compounds producing smaller ones with higher values of FQY.

\section{Conclusions}

Chromophoric organic matter released by fungi strains into aqueous medium without added humate showed similar spectral features for various fungi strains: absorbance values decreasing towards longer wavelengths (with a shoulder at 280-290 nm) and fluorescence emission spectra consisting of two overlapping bands (the UV peak of phenolics and proteins and the blue-green fluorescence of fungal polymers).

The experiments revealed that the effect of microscopic fungi growing in the culture medium with added humate (concentration $0.2 \mathrm{~g} / \mathrm{L}$ ) appeared as changes in the humictype fluorescence: its characteristics became more similar to that of nonliving organic matter in natural waters. Fluorescence quantum yield of humus substances modified by fungi increased, and emission maximum was essentially shifted towards shorter wavelengths compared to that for original solution of commercial humate. Significant transformations of humus substances due to the growth of micro-organisms have been observed typically three weeks after the start of the experiment. Wavelength of emission maximum and quantum yield of humic-type fluorescence became excitation wavelength dependent. The experiments revealed degradation of coal-originated commercial humate due to microbial activity into compounds of smaller molecular size and increased heterogeneity. We resume that transformation of humus substances by fungal cultures can be monitored and characterized using spectral measurements.

\section{Acknowledgments}

Financial support of Russian Foundation for Basic Research (Project 12-04-01230) and the Ministry of Education and
Science of Russia (GK 14.740.11.0796) is deeply appreciated. The authors thank very much Dr. Elena Fedoseeva and Dr. Olga Gorshkova for their experimental contribution.

\section{References}

[1] E. M. Thurman, Organic Geochemistry of Natural Waters, Martinus Nijhoff/W. Junk, Dordrecht, The Netherlands, 1985.

[2] O. S. Yakimenko, "Fulvic acids and the fulvic acid fraction of soil: nature, properties, and isolation methods (A Review)," Eurasian Soil Science, vol. 34, no. 12, pp. 1289-1299, 2001.

[3] O. S. Iakimenko, "Commercial humates from coal and their influence on soil properties and initial plant development," in Use of Humic Substances to Remediate Polluted Environments: From Theory to Practice, I. V. Perminova, K. Hatfield, and N. Hertkorn, Eds., vol. 52 of NATO Science Series: IV: Earth and Environmental Sciences, pp. 365-378, Springer, Dordrecht, The Netherlands, 2005.

[4] N. A. Kulikova, I. V. Perminova, and A. V. Kudryavtsev, "A Comparative study of molecular weight distribution of water-soluble humic substances, humic acids, and fulvic acids extracted from sod-podzolic soils," Moscow University Soil Science Bulletin, vol. 65, no. 4, pp. 155-158, 2010.

[5] O. S. Yakimenko and V. A. Terekhova, "Humic preparations and the assessment of their biological activity for certification purposes," Eurasian Soil Science, vol. 44, no. 11, pp. 1222-1230, 2011.

[6] N. Yu. Grechischeva, H. Pan, G. Budylin, I. V. Perminova, and S. V. Mescheryakov, "Investigation of binding properties of modified humic preparations with respect to pyrene in homogeneous and heterogenic phase," Environmental protection in Oil-Gas Industry, vol. 6, pp. 24-29, 2011.

[7] E. Otabbong, J. Persson, O. Iakimenko, and L. Sadovnikova, "The Ultuna long-term soil organic matter experiment: II. Posphorus status and distribution in soils," Plant and Soil, vol. 195, no. 1, pp. 17-23, 1997.

[8] A. D. Pomogailo, K. A. Kydralieva, A. A. Zaripova et al., "Magnetoactive humic-based nanocomposites," Macromolecular Symposia, vol. 304, no. 1, pp. 18-23, 2011.

[9] A. Zaripova, K. Kydralieva, and S. P. Li, "etal Design of magnetactive nano-hybrid sorbents on the basis of humic substances," Journal of Biological Physics and Chemistry, vol. 8, pp. 121-125, 2008.

[10] A. Yu. Polyakov, A. E. Goldt, T. A. Sorkina, G. A. Davydova, E. A. Goodilin, and I. V. Perminova, "Synthesis of biocompatible magnetic nanoparticles with various micromorphology and their stabilization using humic acids," Prospective Materials, vol. 9, pp. 204-210, 2010. 
[11] J. P. Schmit and G. M. Mueller, "An estimate of the lower limit of global fungal diversity," Biodiversity and Conservation, vol. 16, no. 1, pp. 99-111, 2007.

[12] V. A. Terekhova, "The importance of mycological studies for soil quality control," Eurasian Soil Science, vol. 40, no. 5, pp. 583-587, 2007.

[13] A. A. Rakhleeva, T. A. Semenova, B. R. Striganova, and V. A. Terekhova, "Dynamics of zoomicrobial complexes upon decomposition of plant litter in spruce forests of the southern taiga," Eurasian Soil Science, vol. 44, no. 1, pp. 38-48, 2011.

[14] N. A. Kulikova, I. V. Perminova, G. A. Badun, M. G. Chernysheva, O. V. Koroleva, and E. A. Tsvetkova, "Estimation of uptake of humic substances from different sources by Escherichia coli cells under optimum and salt stress conditions by use of tritium-labeled humic materials," Applied and Environmental Microbiology, vol. 76, no. 18, pp. 6223-6230, 2010.

[15] V. A. Terekhova and T. A. Semenova, "The structure of micromycete communities and their synecologic interactions with basidiomycetes during plant debris decomposition," Mikrobiologiya, vol. 74, no. 1, pp. 91-97, 2005.

[16] T. Osono, Y. Fukasawa, and H. Takeda, "Roles of diverse fungi in larch needle-litter decomposition," Mycologia, vol. 95, no. 5, pp. 820-826, 2003.

[17] A. V. De Santo, F. A. Rutigliano, B. Berg, A. Fioretto, G. Puppi, and A. Alfani, "Fungal mycelium and decomposition of needle litter in three contrasting coniferous forests," Acta Oecologica, vol. 23, no. 4, pp. 247-259, 2002.

[18] M. Jobard, S. Rasconi, and T. Sime-Ngando, "Diversity and functions of microscopic fungi: a missing component in pelagic food webs," Aquatic Sciences, vol. 72, no. 3, pp. 255-268, 2010.

[19] T. K. Goh and K. D. Hyde, "Biodiversity of freshwater fungi," Journal of Industrial Microbiology and Biotechnology, vol. 17, no. 5-6, pp. 328-345, 1996.

[20] M. Bergbauer and S. Y. Newell, "Contribution to lignocellulose degradation and DOC formation from a salt marsh macrophyte by the ascomycete Phaeosphaeria spartinicola," FEMS Microbiology Ecology, vol. 86, no. 4, pp. 341-347, 1992.

[21] Z. Filip and R. Smed-Hildmann, "Does fossil plant material release humic substances into ground water?" Science of the Total Environment, vol. 117-118, pp. 313-324, 1992.

[22] L. A. Grishina, G. N. Koptsik, and M. I. Makarov, Transformation of Soil Organic Matter, Moscow State University, Moscow, Russia, 1990.

[23] K. T. Steffen, A. Hatakka, and M. Hofrichter, "Degradation of humic acids by the litter-decomposing basidiomycete Collybia dryophila," Applied and Environmental Microbiology, vol. 68, no. 7, pp. 3442-3448, 2002.

[24] N. Senesi, "Organic pollutant migration in soils as affected by soil organic matter. Molecular and mechanistic aspects," in Migration and Fate of Pollutants in Soils and Subsoils, D. Petruzzelli and F. G. Helfferich, Eds., vol. 32, pp. 47-74, Springer, Berlin, Germany, 1993.

[25] Z. Filip and J. J. Alberts, "The release of humic substances from Spartina alterniflora (Loisel.) Into sea water as influenced by salt marsh indigenous microorganisms," The Science of the Total Environment, vol. 73, no. 3, pp. 143-157, 1988.

[26] Z. Filip and J. J. Alberts, "Humic substances isolated from Spartina alterniflora (Loisel.) following long-term decomposition in sea water," Science of the Total Environment, vol. 83, no. 3, pp. 273-285, 1989.
[27] Z. Filip, J. J. Alberts, M. V. Cheshire, B. A. Goodman, and J. R. Bacon, "Comparison of salt marsh humic acid with humiclike substances from the indigenous plant species Spartina alterniflora (Loisel)," The Science of the Total Environment, vol. 71, no. 2, pp. 157-172, 1988.

[28] O. V. Koroleva, N. A. Kulikova, T. N. Alekseeva et al., "A comparative characterization of fungal melanin and the humin-like substances synthesized by Cerrena maxima 0275," Prikladnaia Biokhimiia I Mikrobiologiia, vol. 43, no. 1, pp. 69-76, 2007.

[29] I. S. Iavmetdinov, E. V. Stepanova, V. P. Gavrilova, B. V. Lokshin, I. V. Perminova, and O. V. Koroleva, "Isolation and characterization of humin-like substances produced by wooddegrading fungi causing white rot," Prikladnaia Biokhimiia I Mikrobiologiia, vol. 39, no. 3, pp. 293-301, 2003.

[30] P. Baldrian, J. Voříšková, P. Dobiášová, V. Merhautová, L. Lisá, and V. Valášková, "Production of extracellular enzymes and degradation of biopolymers by saprotrophic microfungi from the upper layers of forest soil," Plant and Soil, vol. 338, no. 1-2, pp. 111-125, 2011.

[31] V. A. Terekhova, "Soil bioassay: problems and approaches," Eurasian Soil Science, vol. 44, no. 2, pp. 173-179, 2011.

[32] E. V. Fedoseeva, S. V. Patsaeva, and V. A. Terekhova, "Effect of potassium humate on some of the physiological characteristics of microscopic fungi with different pigments," Mikologiya I Fitopatologiya, vol. 43, no. 3, pp. 243-250, 2009.

[33] R. Reuter, T. H. Badewien, A. Bartholom Ä, A. Braun, A. Lübben, and J. Rullkötter, "A hydrographic time series station in the Wadden Sea (southern North Sea)," Ocean Dynamics, vol. 59, no. 2, pp. 195-211, 2009.

[34] R. Barbini, F. Colao, R. Fantoni, L. Fiorani, N. V. Kolodnikova, and A. Palucci, "Laser remote sensing calibration of ocean color satellite data," Annals of Geophysics, vol. 49, no. 1, pp. 35-43, 2006.

[35] M. Y. Gorbunov, P. G. Falkowski, and Z. S. Kolber, "Measurement of photosynthetic parameters in benthic organisms in situ using a SCUBA-based fast repetition rate fluorometer," Limnology and Oceanography, vol. 45, no. 1, pp. 242-245, 2000.

[36] P. A. Avrorov, A. V. Klimkin, V. P. Maltsev, K. A. Semyanov, and P. A. Tarasov, "Determination of size parameters of isolated microparticles from data on the scattering phase function," in Atmospheric and Oceanic Optics, vol. 19, no. 2-3, pp. 179-182, 2006.

[37] L. Fiorani, R. Fantoni, A. Lai et al., "Simultaneous measurement of size, refractive index, depolarization and fluorescence of phytoplankton cells by laser scanning flow cytometry," EARSeL eProceedings, vol. 6, pp. 47-57, 2007.

[38] M. Y. Gorbunov, Z. S. Kolber, M. P. Lesser, and P. G. Falkowaski, "Photosynthesis and photoprotection in symbiotic corals," Limnology and Oceanography, vol. 46, no. 1, pp. 75-85, 2001.

[39] S. A. Dovyd'kov, A. M. Baulin, B. V. Trubitsin, V. A. Karavaev, and A. N. Tikhonov, "Effect of inorganic phosphate on the functioning of photosynthetic apparatus in bean leaves," Biofizika, vol. 45, no. 2, pp. 360-361, 2000.

[40] V. A. Karavaev, M. K. Solntsev, A. M. Kunznetsov et al., "Changes in slow fluorescence induction of maple leaves near urban highways," Biofizika, vol. 46, no. 2, pp. 361-382, 2001.

[41] V. A. Karavaev, M. K. Solntsev, T. P. Iurina, E. V. Iurina, I. B. Poliakova, and A. M. Kuznetsov, "Antifungal activity of aqueous extracts from the leaf of cowparsnip and comfrey," Biology Bulletin, vol. 28, no. 4, pp. 365-370, 2001. 
[42] I. B. Poliakova, V. A. Karavaev, M. K. Solntsev, and A. A. chechulina, "Luminescent indicators in various parts of wheat leaves in ontogenesis," Biofizika, vol. 48, no. 6, pp. 1108-1115, 2003.

[43] N. L. Fateyeva, A. V. Klimkin, O. V. Bender, A. P. Zotikova, and M. S. Yamburov, "Analysis of laser-induced fluorescence in wood plants under nitrogen soil pollution," Atmospheric and Oceanic Optics, vol. 19, no. 2-3, pp. 189-192, 2006.

[44] B. G. Ageev, A. P. Zotikova, V. A. Kapitanov et al., "Complex test bench for optical diagnostics of biosystems," Atmospheric and Oceanic Optics, vol. 20, no. 1, pp. 82-86, 2007.

[45] V. A. Karavaev, L. E. Gunar, A. G. Myakinkov et al., "Slow fluorescence induction and productivity of barley treated with supercritical fluid extracti of amaranth," Biophysics, vol. 57, no. 4, pp. 662-664, 2012.

[46] S. A. Glazunova, V. V. Ptushenko, L. E. Gunar, V. A. Karavaev, M. K. Solntsev, and A. N. Tikhonov, "Slow fluorescence induction and $\mathrm{CO}_{2}$-exchange in bean leaves treated with Reynoutria sachalinensis extract," Biofizika, vol. 54, no. 3, pp. 492-494, 2009.

[47] E. G. Maksimov, G. V. Tsoraev, V. Z. Paschenko, and A. B. Rubin, "The nature of anomalous temperature dependence of the fluorescence lifetime of allophycocyanin," Doklady Biochemistry and Biophysics, vol. 443, no. 1, pp. 86-90, 2012.

[48] V. Z. Paschenko, N. V. Konovalova, A. L. Bagdashkin, V. V. Gorokhov, V. B. Tusov, and V. I. Yuzhakov, "Excitation energy transfer in covalently bonded porphyrin heterodimers," Optics and Spectroscopy, vol. 112, no. 4, pp. 519-527, 2012.

[49] V. Z. Paschenko, V. V. Gorokhov, B. N. Korvatovsky et al., "Electrochemical shift of the carotenoid molecule absorption band as an indicator of processes of energy migration in the reaction center of Rhodobacter sphaeroides," Doklady Biochemistry and Biophysics, vol. 434, no. 1, pp. 257-261, 2010.

[50] D. O. Vetkin, E. T. Gainullina, V. A. Karavaev, R. N. Nurmukhametov, S. B. Ryzhikov, and V. F. Taranchenko, "Study of cholinesterase active site using a fluorescent probe," Biology Bulletin, no. 2, pp. 157-162, 2004.

[51] E. T. Gainullina, K. V. Kondratyev, S. B. Ryzhikov, and V. F. Taranchenko, "Fluorescent method for evaluation of cholinesterase inhibitors," Bulletin of Experimental Biology and Medicine, vol. 142, no. 6, pp. 751-752, 2006.

[52] P. G. Coble, S. A. Green, N. V. Blough, and R. B. Gagosian, "Characterization of dissolved organic matter in the Black Sea by fluorescence spectroscopy," Nature, vol. 348, no. 6300, pp. 432-435, 1990.

[53] K. Mopper and C. A. Schultz, "Fluorescence as a possible tool for studying the nature and water column distribution of DOC components," Marine Chemistry, vol. 41, no. 1-3, pp. 229-238, 1993.

[54] J. J. Alberts and M. Takács, "Comparison of the natural fluorescence distribution among size fractions of terrestrial fulvic and humic acids and aquatic natural organic matter," Organic Geochemistry, vol. 35, no. 10, pp. 1141-1149, 2004.

[55] M. M. D. Sierra, M. Giovanela, E. Parlanti, and E. J. SorianoSierra, "Fluorescence fingerprint of fulvic and humic acids from varied origins as viewed by single-scan and excitation/emission matrix techniques," Chemosphere, vol. 58, no. 6, pp. 715-733, 2005.

[56] A. S. Milyukov, S. V. Patsaeva, V. I. Yuzhakov, O. M. Gorshkova, and E. M. Prashchikina, "Fluorescence of nanoparticles of organic matter dissolved in natural water," Moscow University Physics Bulletin, vol. 6, pp. 368-372, 2007.
[57] D. M. Shubina, S. V. Patsaeva, V. I. Yuzhakov, O. M. Gorshkova, and E. V. Fedoseeva, "Fluorescence of organic matter dissolved in natural water," Water: Chemistry and Ecology, vol. 11, pp. 31-37, 2010

[58] D. Shubina, E. Fedoseeva, O. Gorshkova et al., "The "blue shift" of emission maximum and the fluorescence quantum yield as quantitative spectral characteristics of dissolved humic substances," EARSeL eProceedings, vol. 9, no. 1, pp. 13-21, 2010.

[59] C. Xiaoli, L. Guixiang, Z. Xin, H. Yongxia, and Z. Youcai, "Fluorescence excitation-emission matrix combined with regional integration analysis to characterize the composition and transformation of humic and fulvic acids from landfill at different stabilization stages," Waste Management, vol. 32, no. 3, pp. 438-447, 2012.

[60] C. Richard, C. Coelho, G. Guyot, L. Shaloiko, O. Trubetskoj, and O. Trubetskaya, "Fluorescence properties of the $<5 \mathrm{kDa}$ molecular size fractions of a soil humic acid," Geoderma, vol. 163, no. 1-2, pp. 24-29, 2011.

[61] O. Trubetskaya, O. Trubetskoj, G. Guyot, F. Andreux, and C. Richard, "Fluorescence of soil humic acids and their fractions obtained by tandem size exclusion chromatographypolyacrylamide gel electrophoresis," Organic Geochemistry, vol. 33, no. 3, pp. 213-220, 2002.

[62] N. L. Lavrik and N. U. Mulloev, "A Method to study polydispersity of humic acid from fluorescence quenching by $\mathrm{Cu}^{2+}$ ions," Journal of Applied Spectroscopy, vol. 78, no. 5, pp. 705-710, 2011.

[63] O. Y. Gosteva, A. A. Izosimov, S. V. Patsaeva, V. I. Yuzhakov, and O. S. Yakimenko, "Fluorescence of industrial humic substances in water," Journal of Applied Spectroscopy, vol. 78, no. 6, pp. 943-950, 2011.

[64] V. Řezáčová and M. Gryndler, "Fluorescence spectroscopy: a tool to characterize humic substances in soil colonized by microorganisms?" Folia Microbiologica, vol. 51, no. 3, pp. 215-221, 2006.

[65] D. F. Eaton, "Reference materials for fluorescence measurement," Pure and Applied Chemistry, vol. 60, pp. 1107-1114, 1988.

[66] C. Belin, C. Quellec, M. Lamotte, M. Ewald, and P. Simon, "Characterization by fluorescence of the dissolved organic matter in natural water. Application to fractions obtained by tangential ultrafiltration and XAD resin isolation," Environmental Technology, vol. 14, no. 12, pp. 1131-1144, 1993.

[67] M. M. De Souza Sierra, O. F. X. Donard, M. Lamotte, C. Belin, and M. Ewald, "Fluorescence spectroscopy of coastal and marine waters," Marine Chemistry, vol. 47, no. 2, pp. 127-144, 1994. 

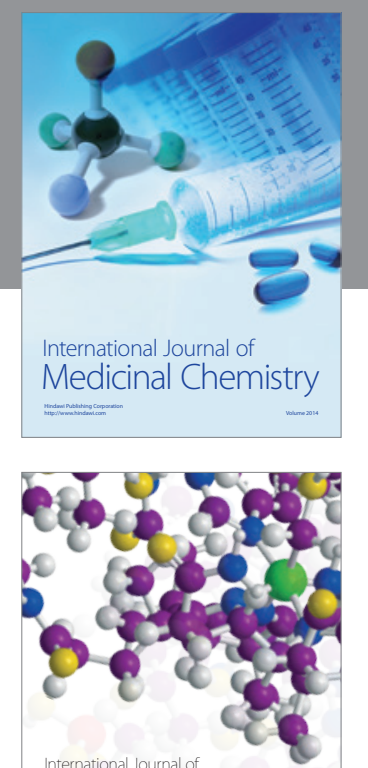

\section{Carbohydrate} Chemistry

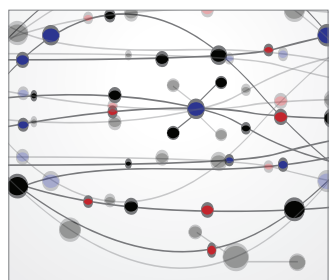

The Scientific World Journal
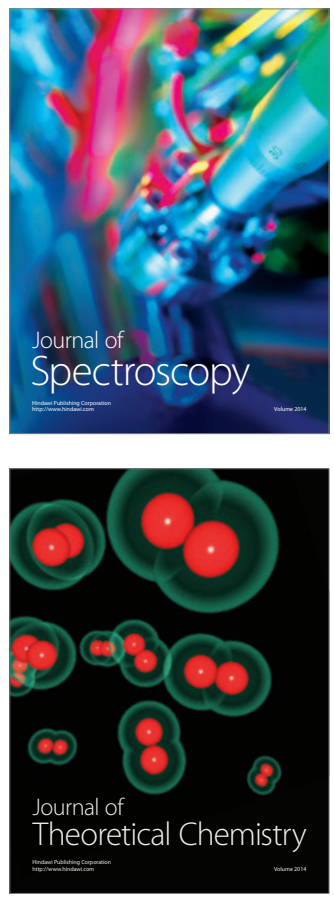
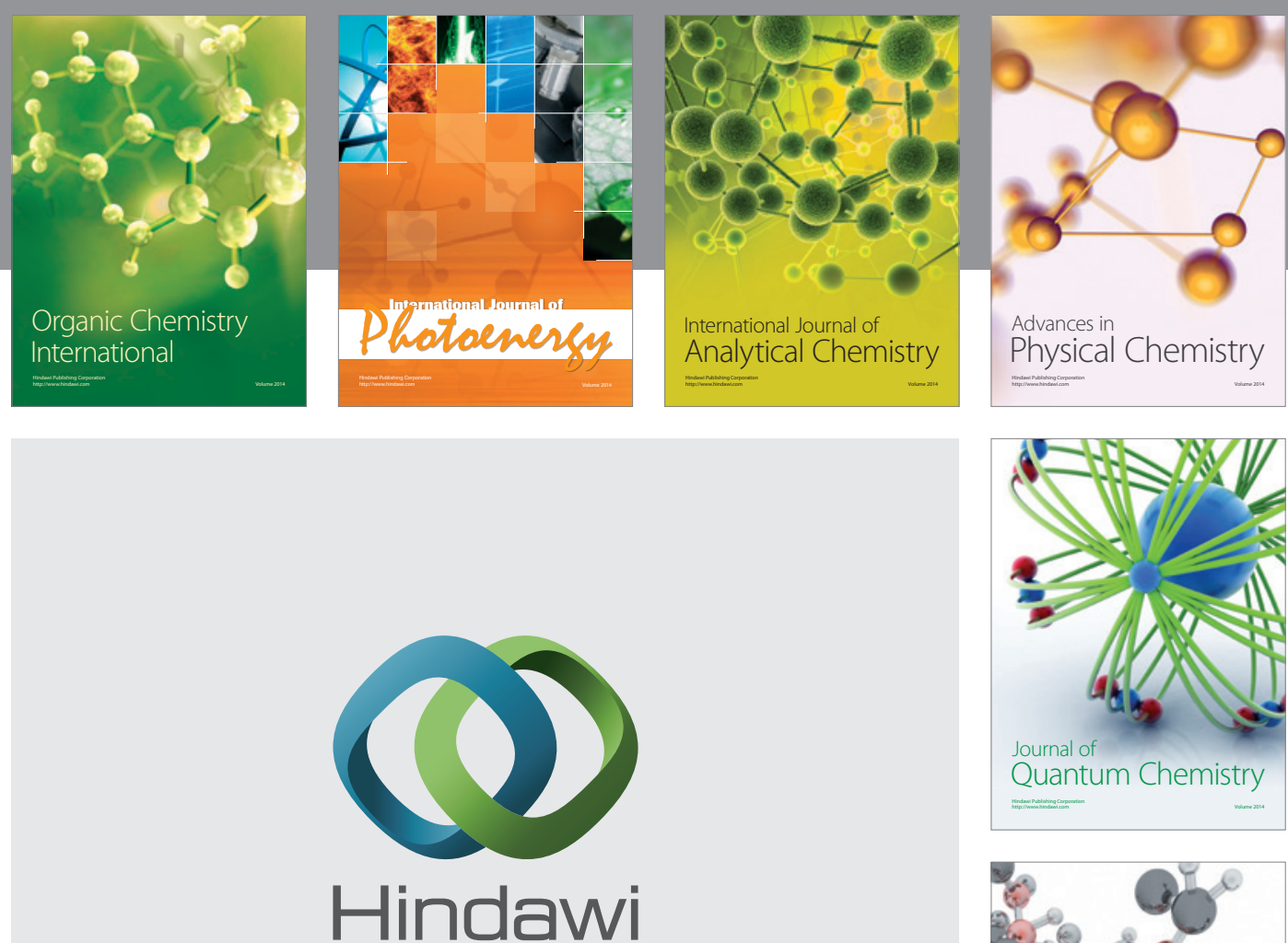

Submit your manuscripts at

http://www.hindawi.com

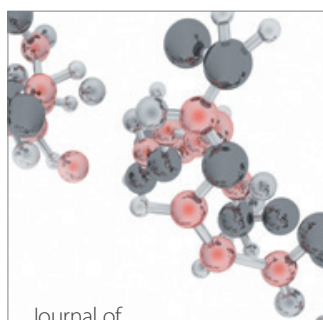

Analytical Methods

in Chemistry

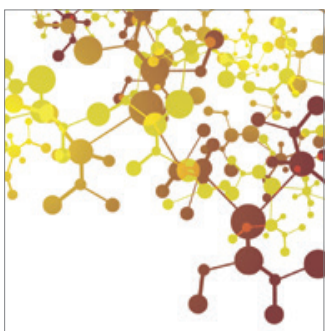

Journal of

Applied Chemistry

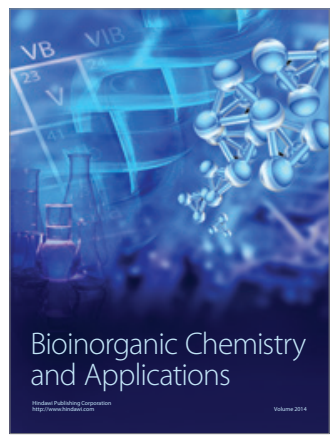

Inorganic Chemistry
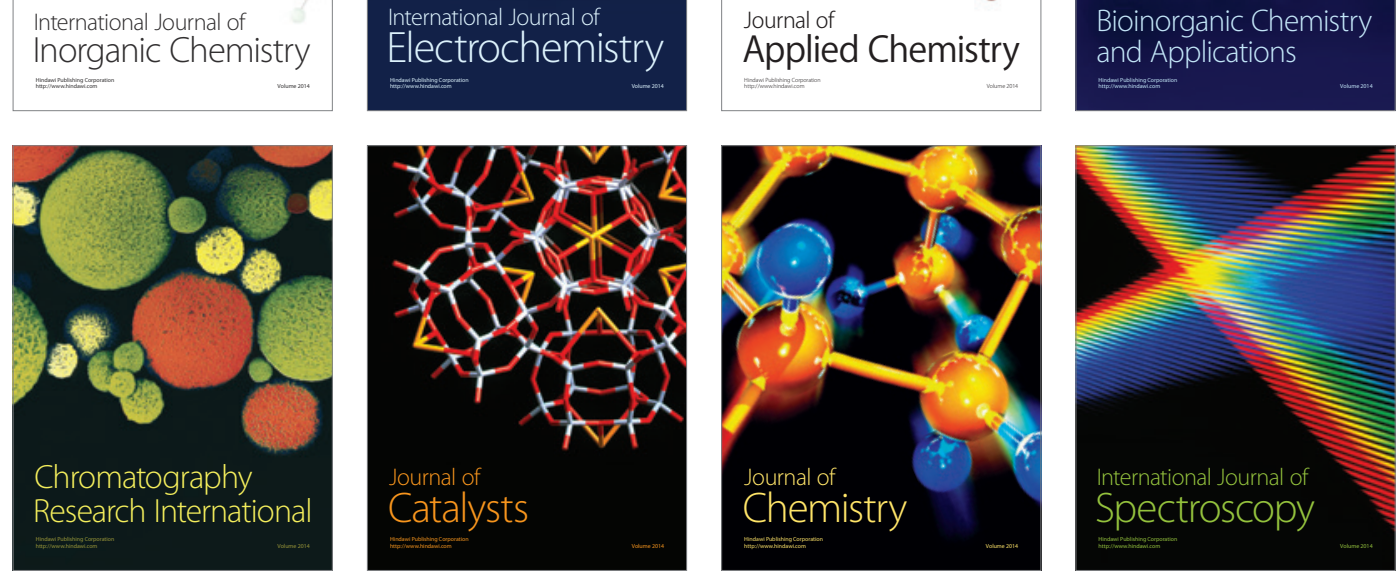